\title{
Multiplex proteomics identifies novel CSF and plasma biomarkers of early Alzheimer's disease
}

\author{
Christopher D. Whelan ${ }^{1 \dagger}$ (D), Niklas Mattsson ${ }^{2,3+}$, Michael W. Nagle ${ }^{4 \dagger}$, Swetha Vijayaraghavan ${ }^{5}$, Craig Hyde $^{4}$, \\ Shorena Janelidze², Erik Stomrud², Julie Lee, Lori Fitz ${ }^{4}$, Tarek A. Samad ${ }^{6}$, Gayathri Ramaswamy ${ }^{1}$, \\ Richard A. Margolin ${ }^{7}$, Anders Malarstig ${ }^{4,5^{*}}$ and Oskar Hansson ${ }^{2,8^{*}}$
}

\begin{abstract}
To date, the development of disease-modifying therapies for Alzheimer's disease (AD) has largely focused on the removal of amyloid beta A $\beta$ fragments from the CNS. Proteomic profiling of patient fluids may help identify novel therapeutic targets and biomarkers associated with AD pathology. Here, we applied the Olink ${ }^{\text {TM }}$ ProSeek immunoassay to measure 270 CSF and plasma proteins across 415 A $\beta$ - negative cognitively normal individuals ( $A \beta$ $C N), 142 \mathrm{~A} \beta$-positive $C N(A \beta+C N), 50 A \beta$ - mild cognitive impairment (MCl) patients, $75 A \beta+\mathrm{MCl}$ patients, and 161 $A \beta+A D$ patients from the Swedish BioFINDER study. A validation cohort included $59 A \beta-C N, 23 A \beta-+C N, 44 A \beta-$ $\mathrm{MCl}$ and $53 \mathrm{~A} \beta+\mathrm{MCl}$. To compare protein concentrations in patients versus controls, we applied multiple linear regressions adjusting for age, gender, medications, smoking and mean subject-level protein concentration, and corrected findings for false discovery rate (FDR, $q<0.05)$. We identified, and replicated, altered levels of ten CSF proteins in $A \beta+$ individuals, including CHIT1, SMOC2, MMP-10, LDLR, CD200, EIF4EBP1, ALCAM, RGMB, tPA and $\operatorname{STAMBP}(-0.14<d<1.16 ; q<0.05)$. We also identified and replicated alterations of six plasma proteins in A $\beta+$ individuals OSM, MMP-9, HAGH, CD200, AXIN1, and UPA $(-0.77<d<1.28 ; q<0.05)$. Multiple analytes associated with cognitive performance and cortical thickness $(q<0.05)$. Plasma biomarkers could distinguish AD dementia $(A \cup C=0.94,95 \% \mathrm{Cl}=0.87-0.98)$ and prodromal $A D(A \cup C=0.78,95 \% \mathrm{Cl}=0.68-0.87)$ from $C N$. These findings reemphasize the contributions of immune markers, phospholipids, angiogenic proteins and other biomarkers downstream of, and potentially orthogonal to, $A \beta$ - and tau in AD, and identify candidate biomarkers for earlier detection of neurodegeneration.
\end{abstract}

Keywords: Alzheimer's disease, Mild cognitive impairment, Biomarker, Proteomics, Inflammation, Apoptosis, Angiogenesis

\section{Introduction}

Alzheimer's disease (AD) is the most common cause of dementia, affecting one in 10 people aged 65 years or older [3]. To date, the development of diseasemodifying treatments for $\mathrm{AD}$ has largely targeted one of its pathological hallmarks, amyloid beta $(A \beta)$, and to a lesser extent tau, with notably high failure rates

\footnotetext{
* Correspondence: Anders.Malarstig@pfizer.com; Hansson@med.lu.se ${ }^{\dagger}$ Christopher D. Whelan, Niklas Mattsson and Michael W. Nagle contributed equally to this work.

${ }^{4}$ Pfizer Worldwide Research \& Development, Cambridge, MA 02139, USA

${ }^{2}$ Clinical Memory Research Unit, Department of Clinical Sciences, Lund

University, Lund, Sweden

Full list of author information is available at the end of the article
}

in clinical trials [12]. Molecular markers such as amyloid PET, cerebrospinal fluid (CSF) A $\beta$, and CSF tau are frequently employed in the clinical diagnosis of $\mathrm{AD}$, and biomarkers are increasingly recognized as integral components of the drug development pipeline [10]. However, recent evidence from human genetics [45, 52], neuroimaging [14], and in-vivo modeling [9] has strongly implicated additional disease mechanisms in $\mathrm{AD}$, not reflected by the established $\mathrm{A} \beta$ and tau biomarkers. These potential pathophysiological processes, such as inflammation $[14,52]$, membrane phospholipid dysregulation [62], and neurovascular

(C) The Author(s). 2019 Open Access This article is distributed under the terms of the Creative Commons Attribution 4.0 International License (http://creativecommons.org/licenses/by/4.0/), which permits unrestricted use, distribution, and 
disruption [45], are less frequently targeted, and remain less well understood [22].

Proteomics, the analysis of proteins in different bodily tissues and fluids, can be used to study myriad pathways putatively affected in AD in-vivo, before the onset of overt neurodegeneration, thus potentially elucidating important disease mechanisms and informing future pharmacotherapeutic trials. In CSF, certain proteomic assays can reflect underlying brain pathology [48], and thus, may be useful for pharmacokinetic monitoring, diagnosis, and stratification [5]. However, lumbar puncture is invasive. Blood may serve as a more accessible body fluid; however, many blood-based molecular profiling studies of AD have been restricted by small sample sizes, methodological variability, and suboptimal diagnostic sensitivity $[28,38]$. Additionally, with the exception of certain blood biomarkers, such as plasma $A \beta$ [39] and plasma tau [28], few studies have directly explored the relationship between CSF proteins and their blood-based analogs in the same cohort; thus, the extent to which peripheral molecular changes accurately reflect CNS dynamics has yet to be characterized at large scale.

Here, we sought to understand the contributions of proteins downstream of, and potentially orthogonal to, $\mathrm{A} \beta$ and tau across the preclinical, prodromal, and dementia stages of AD. We measured a diverse panel of 270 proteins in the CSF and plasma of up to 1022 individuals, using a validated, highly sensitive and specific immunoassay [4]. We identified, and replicated, evidence of differential regulation in proteins related to innate and adaptive immunity (CD200, CHIT1, MMP-9, MMP10 , oncostatin-M, STAMBP), membrane phospholipids (LDLR), axon guidance, cell adhesion and differentiation (ALCAM, RGMB, ROBO2), ischemic injury (uPA, tPA, SMOC2), mTOR and Wnt/ $\beta$-catenin signaling (AXIN1, EIF4EBP1), and glucose metabolism (HAGH) in early and later-stage $\mathrm{AD}$. Multiple proteins associated with baseline cortical thickness and cognitive performance. Approximately half of all assayed proteins in CSF showed modest correlations with their analogs in plasma, and a combination of plasma analytes could differentiate $\mathrm{AD}$ from non-AD with high accuracy. Thus, our findings reemphasize the importance of targeting pathways beyond $A \beta$ and tau in $A D$, and identify several candidate biomarkers for early detection of brain pathology, pending additional validation.

\section{Materials and methods}

\section{Standard protocol approvals, registrations, and patient consents}

The study was approved by the Regional Ethics Committee in Lund, Sweden. Written informed consent was collected from all participants.

\section{Study participants}

Participants were recruited from southern Sweden between 2009 and 2014 as part of the prospective and longitudinal BioFINDER study (www.biofinder.se). A total of 872 participants assessed at the Memory Clinic in Malmö were recruited to the discovery cohort, including 565 cognitively normal elderly participants $(\mathrm{CN}), 131$ patients with mild cognitive impairment (MCI), and 176 patients with dementia due to AD (see Table 1). An additional 179 participants assessed at the Memory Clinic in Lund were recruited to the replication cohort, including 82 elderly participants who presented with memory complaints but were clinically determined to be cognitively normal, and $97 \mathrm{MCI}$ patients (see Additional file 1: Table S6).

Cognitively normal elderly participants were included as study controls if they (i) were aged $60-80$ years, (ii) had Mini-mental State Examination (MMSE) scores of 28-30 at their initial screening visit, (iii) lacked symptoms of cognitive impairment, as assessed by a physician, and (iv) did not fulfill the criteria for MCI or dementia. Participants were excluded from the control group if they (i) refused lumbar puncture, or if they presented with (i) a significant neurological or psychiatric disease (iii) current alcohol or substance misuse, or (iv) a systematic illness preventing them from participating in the study.

Patients with MCI were recruited from a larger cohort of non-demented outpatients with cognitive symptoms; the inclusion criteria for this cohort included (i) age 6080 years, (ii) initial presentation with a complaint related to memory, executive, visuo-spatial, language praxis, or psychomotor function, (iii) an MMSE score between 24 and 30, (iv) significant impairment in at least one cognitive domain (most often memory) according to an assessment by an experienced neuropsychologist [26] and (iv) essentially preserved activities of daily living. Exclusion criteria included (i) fulfillment of the criteria for any dementia disorder, (ii) cognitive impairment that could be definitively explained by another condition, (iii) a systemic illness preventing them from participating in the study, and (iv) refusal to undergo lumbar puncture or neuropsychological assessment.

$\mathrm{AD}$ dementia patients were classified using the criteria for probable AD, as defined by NINCDS-ADRDA [29].

Participants were grouped based on a combination of their clinical diagnosis $(\mathrm{AD}, \mathrm{MCI}$, or $\mathrm{CN})$ and $\mathrm{CSF} A \beta$ pattern, based on combined $A \beta 40$ and $A \beta 40$ assays (Eurimmun, Germany). Individuals with a CSF $A \beta 42 / A \beta 40$ ratio $\geq 0.1$ were considered amyloid-negative controls $(\mathrm{A} \beta-\mathrm{CN})$ or patients with $\mathrm{MCI}$ not due to $\mathrm{AD}(\mathrm{A} \beta-$ $\mathrm{MCI}$ ), and individuals with a ratio $\leq 0.1$ were considered amyloid-positive cognitively normal participants $(A \beta+$ $\mathrm{CN})$, or patients with $\mathrm{MCI}$ due to $\mathrm{AD}(\mathrm{A} \beta+\mathrm{MCI})[20$, 
Table 1 Demographic and clinical data for the Memory Malmö 'discovery' cohort

\begin{tabular}{|c|c|c|c|c|c|c|}
\hline & Control $A \beta-$ & Control $A \beta+$ & $\mathrm{MCl}-\mathrm{A} \beta-$ & $\mathrm{MCl}-\mathrm{A} \beta+$ & $A D(A \beta+)$ & P-value (group differences) \\
\hline Sample size (n) & 415 & 142 & 50 & 75 & 161 & \\
\hline $\operatorname{Sex}(F / M)$ & 256/159 & $100 / 42$ & $20 / 30$ & $33 / 42$ & $104 / 57$ & 0.000061 \\
\hline Mean age in years (SD) & $71.7(5.21)$ & $72.99(4.78)$ & $68.8(5.12)$ & $72.29(4.93)$ & $74.58(7.37)$ & $1.676 \times 10-10$ \\
\hline MMSE mean (SD) & $29.11(0.9)$ & $29.02(0.83)$ & $27.3(1.68)$ & $26.56(1.79)$ & $21.47(3.9)$ & $9.4022 \times 10-213$ \\
\hline APOE (1 or $2 \varepsilon 4$ alleles) & $22.89 \%$ & $57.75 \%$ & $20 \%$ & $74.67 \%$ & $66.46 \%$ & $7.0724 \times 10-32$ \\
\hline Anti-inflammatory drugs & $9.64 \%$ & $7.75 \%$ & $4.00 \%$ & $9.33 \%$ & $6.21 \%$ & 0.52 \\
\hline Platelet inhibitor drugs & $16.39 \%$ & $17.61 \%$ & $38.00 \%$ & $33.33 \%$ & $29.19 \%$ & 0.000016 \\
\hline Antidepressive drugs & $6.75 \%$ & $7.04 \%$ & $32.00 \%$ & $16.00 \%$ & $22.98 \%$ & $1.3371 \times 10-10$ \\
\hline Lipid-lowering drugs & $26.02 \%$ & $30.99 \%$ & $42.00 \%$ & $37.33 \%$ & $29.81 \%$ & 0.07 \\
\hline Antihypertensive/cardioprotective drugs & $41.69 \%$ & $49.30 \%$ & $54 \%$ & $52 \%$ & $54.04 \%$ & 0.04 \\
\hline Current smoker & $9.4 \%$ & $2.82 \%$ & $8 \%$ & $5.33 \%$ & $9.94 \%$ & 0.08 \\
\hline Mean $A \beta 42$ in pg/ml (SD) & $752(253)$ & $423(175)$ & $628(223)$ & $280(90)$ & $305(132)$ & $6.3545 \times 10-119$ \\
\hline Mean $A \beta 40$ in pg/ml (SD) & $5847(2042)$ & $6566(2373)$ & $4956(2045)$ & $5057(1612)$ & $5470(2179)$ & $4.9837 \times 10-8$ \\
\hline A $342 / 40$ ratio - log2 transformed (SD) & $2.05(0.17)$ & $2.75(0.28)$ & $2.05(0.17)$ & $2.89(0.28)$ & $2.9(0.29)$ & $7.8397 \times 10-253$ \\
\hline Mean total tau (SD) & $292(89)$ & $432(163)$ & $295(110)$ & $515(181)$ & $649(221)$ & \\
\hline Mean phospho-tau (SD) & $37(13)$ & $66(35)$ & $40(17)$ & $105(46)$ & $123(47)$ & \\
\hline
\end{tabular}

Demographics are provided for participants who were included in the final proteomics analysis after quality assessment (see Methods)

${ }^{a}$ To assess group differences we used a test of independence (Chi-square) for categorical variables and ANOVA for continuous variables

41]. All patients with dementia due to $\mathrm{AD}$ had pathological CSF ratios $\geq 0.1$. The CSF $A \beta 42 / A \beta 40$ ratio was used instead of CSF $A \beta 42$ alone, as this ratio has a greater concordance with amyloid PET findings [20, 41]. $A \beta-$ MCI patients were included in the study for comparison with $A \beta+$ patients, since proteins showing evidence of differential regulation across Ab-positive and Ab-negative groups could potentially implicate processes orthogonal to $A \beta$ deposition.

Following quality control, the Memory Malmö discovery cohort consisted of $415 \mathrm{~A} \beta-\mathrm{CN}$ participants, 142 $\mathrm{A} \beta+\mathrm{CN}$ participants, $50 \mathrm{~A} \beta-\mathrm{MCI}$ patients, $75 \mathrm{~A} \beta+\mathrm{MCI}$ patients, and $161 \mathrm{AD}$ patients (see Table 1 for participant demographics). The Memory Lund replication cohort consisted of $59 \mathrm{~A} \beta-\mathrm{CN}$ participants, $23 \mathrm{~A} \beta+\mathrm{CN}$ participants, $44 \mathrm{~A} \beta-\mathrm{MCI}$ patients, and $53 \mathrm{~A} \beta+\mathrm{MCI}$ patients (see Additional file 1: Table S6 for participant demographics).

\section{Magnetic resonance imaging}

MRI data were collected from 303 healthy elderly controls and $112 \mathrm{MCI}$ patients from the Memory Malmö cohort, using a 3 Tesla Siemens ${ }^{\circ}$ Trio scanner equipped with a standard 12-channel head coil. Hippocampal volume and cortical thickness estimates were measured using FreeSurfer v5.3 (https://surfer/nmr.mgh.harvard.edu). A composite AD 'signature cortical thickness' measurement was constructed by calculating mean surface-area adjusted thickness across the entorhinal, inferior temporal, middle temporal, and fusiform cortices bilaterally [17]. Hippocampal volume measures were adjusted for total intracranial volume. Full details of MRI processing are described elsewhere [40].

\section{Plasma and CSF sampling}

Plasma and lumbar CSF samples were collected from non-fasting participants during the 'subjects' baseline BioFINDER visit. and analyzed following a standardized protocol [40]. After collection, samples were centrifuged (2000 g, $+4{ }^{\circ} \mathrm{C}, 10 \mathrm{~min}$ ), aliquoted into $1 \mathrm{ml}$ polypropylene tubes (Sarstedt AG \& Co., Nümbrecht, Germany), and stored at $-80^{\circ} \mathrm{C}$. Prior to proteomic screening, all plasma and CSF samples underwent one freeze-thaw cycle, and were further aliquoted into 200L Lobind tubes (Eppendorf Nordic A/S, Denmark).

\section{Protein quantification}

Protein concentrations were quantified using the validated, highly sensitive and specific ProSeek multiplex immunoassay, developed by Olink Proteomics (Uppsala, Sweden) [4]. Three commercially available ProSeek $^{\circ}$ Multiplex panels were used to measure the concentrations of 270 proteins in human plasma and CSF (Additional file 1: Table S1). Protein measurements were conducted using Proximity Extension Assay (PEA) technology, following the manufacturer's protocol [4]. Briefly, antigens were incubated with pairs of antibodies containing DNA oligonucleotides bound to each of the 270 proteins to be measured. A template for hybridization and extension was generated by 
oligonucleotides in close proximity, and preamplification was performed using polymerase chain reaction (PCR). Following digestion of residual primers, specific primers were digested on a quantitative realtime PCR chip (Dynamic Array IFC; Fluidigm Biomark) using a Biomark HD Instrument. Protein quantities were produced as normalized protein expression (NPX) values on the $\log _{2}$ scale.

\section{Patient-level quality control}

Samples from 1051 participants (872 discovery samples, 179 replication samples) were randomized and assayed in parallel on 54 ProSeek plates in plasma and 55 ProSeek plates in CSF. Four internal controls were added to each sample to monitor assay performance and the quality of individual samples, and intensity normalization was implemented to minimize technical variation between plates. The quality of each sample was assessed by evaluating deviation from the median value of its internal control; samples that deviated less than $0.3 \mathrm{NPX}$ from the median passed quality assessment.

\section{Protein-level quality control}

Proteins detected in more than $70 \%$ of samples were considered sufficient to allow statistical analysis using standard regression models. Only proteins with less than $20 \%$ of values below the reported lower limit of quantification (LLQ) were analyzed quantitatively. In these instances, we used the actual raw extended values (under LLQ), provided by OLINK, to impute best-guess values. A histogram was made of each such protein to verify a continuous distribution of values across the LLQ threshold when using these extended values.

Principal component analyses (PCAs) were generated on the NPX values and visually inspected to identify possible outliers and to evaluate the consistency of plasma and CSF data.

\section{Statistical analysis}

All statistical analyses and data processing were conducted using $\mathrm{R}$ version 3.4.4 and IBM SPSS Statistics for Windows 22.0. All univariate linear regressions and mixed-effects models conducted in the discovery cohort were adjusted for False Discovery Rate (FDR) at an FDRadjusted $p$-value (i.e. $q$ value) threshold of 0.05 , using the p.adjust function in R. For proteins surviving FDR adjustment in the discovery cohort, unadjusted $p$-values were inspected in the replication cohort.

\section{Univariate linear regressions}

Differential regulation of proteins was assessed between the cognitively normal, $\mathrm{A} \beta$ - elderly $\mathrm{CN}$ and; (i) cognitively normal, $A \beta+$ elderly individuals, (ii) $A \beta-$ MCI patients, (iii) $\mathrm{A} \beta+\mathrm{MCI}$ patients, and (iv) patients with dementia due to $\mathrm{AD}$, using multiple linear regressions via the $l m$ function in $\mathrm{R}$, where clinical grouping was the predictor of interest, and protein concentration in plasma or CSF was the outcome measure. Age, gender, current smoking status, medications (including platelet inhibitors, antidepressants, anti-inflammatory, lipidlowering, antihypertensive, and cardioprotective drugs), and cross-subject mean protein concentration, collectively referred to as 'standard covariates', were included in all models. For brevity, comparisons between clinical groups (AD versus $A \beta+M C I, A \beta+M C I$ versus $A \beta+C N$, $A D$ versus $A \beta+C N$ ) were omitted from the main text, but included in the Additional file 1: (see Additional file 1: Note 1 and Tables S23-S28).

\section{Multivariate LASSO regression}

We employed multivariable modeling to identify subsets of proteins that could accurately discriminate cognitively normal healthy individuals from cognitively normal $A \beta+$ individuals, $\mathrm{MCI}$, and $\mathrm{AD}$-dementia. Our model evaluated several different proteins simultaneously, using the least absolute shrinkage and selection operator method (LASSO; [55], implemented via the glmnet package in R. We separately tested models to predict $A \beta-M C I, A \beta+$ $\mathrm{MCI}$, and $\mathrm{AD}$-dementia patients, versus $\mathrm{A} \beta$ - controls, adjusting for age and gender. The LASSO regularization parameter lambda was selected by 10 -fold crossvalidation using the cv.glmnet function, to protect against overfitting. Results from the LASSO models are presented as the mean and $95 \% \mathrm{CI}$ of the cross-validated area under the receiver operating characteristics curves (AUC). In a supplementary analysis, we employed a more complex LASSO model which adjusted for the standard covariates (Additional file 1: Note 2).

\section{Associations with clinical and neuroimaging endpoints}

Associations between circulating proteins and MiniMental State Examination (MMSE; collected for all participants) and Clinical Dementia Rating Scale Sum of Boxes (CDR-SB; collected for healthy elderly and $\mathrm{MCI}$ ) were assessed using multiple linear regressions in R, where baseline MMSE or CDR-SB score was the determinant of interest, and protein concentration was the outcome measure, adjusting for the standard covariates.

Associations between circulating proteins, hippocampal volume, and signature cortical thickness were assessed using multiple linear regressions in $R$, again adjusting for the standard covariates.

\section{Within- and between-fluid correlations}

Within-fluid correlations (CSF-to-CSF, plasma-toplasma) and between-fluid correlations (CSF-to-plasma) 
were assessed across all proteins using a simple Pearson correlation test in R.

\section{Results \\ 190 CSF proteins and 250 plasma proteins were analyzed across 843 discovery samples and 179 replication samples}

Due to technical issues, no data were recorded from the BDNF and CCL22 assays. An additional 68 CSF proteins and 18 plasma proteins were excluded due to low detection rates $(<70 \%$; Additional file 1 : Table S1). Thus, our final statistical analyses included 190 proteins that were detected in $>70 \%$ of CSF samples, and 250 proteins that were detected in $>70 \%$ of plasma samples.

Of the 1051 samples, 29 failed due to missingness of $10 \%$ or more analytes in CSF. 31 samples (including the aforementioned 29 samples) had missingness rates of $10 \%$ or more in plasma. The remaining samples had no more than five missing values (representing 1.8\% of all analytes). A single healthy elderly participant was identified as an outlier in plasma, due to a covariate-adjusted PCA value more than 3.5 standard deviations from the centroid (Additional file 1: Figs. S1-S8). Thus, of the initial 1051 participants, 1022 were eligible for plasma analysis, and 1019 were eligible for CSF analysis.
CSF levels of CHIT1, MMP-10, SMOC2, and ezrin were increased in $A D$ and $A \beta$-positive $\mathrm{MCl}$

Compared to $A \beta$ - cognitively normal $(\mathrm{CN})$ elderly controls, AD-dementia and $\mathrm{A} \beta+\mathrm{MCI}$ patients both showed significant increases of four proteins in CSF, including chitinase 1 (CHIT1; $d=0.95$ in $\mathrm{A} \beta+\mathrm{MCI} ; d=0.76$ in $\mathrm{AD}$; $q<6.07 \times 10^{-7}$ ), matrix metalloproteinase 10 (MMP-10; $d=0.32$ in $\mathrm{A} \beta+\mathrm{MCI} ; d=0.54$ in $\left.\mathrm{AD} ; q<1.16 \times 10^{-5}\right)$, $\mathrm{SMOC} 2(d=0.29$ in $\mathrm{A} \beta+\mathrm{MCI} ; d=0.28$ in $\mathrm{AD} ; q<1.16 \times$ $\left.10^{-5}\right)$, and ezrin $(d=0.13$ in $\mathrm{A} \beta+\mathrm{MCI} ; d=0.24 q<0.05$; see Fig. $1 \mathrm{a}$ and Table 2). An additional five CSF proteins were increased, and 13 CSF proteins were decreased, in AD-dementia patients only, while an additional three proteins were increased in $\mathrm{A} \beta+\mathrm{MCI}$ patients only, when compared to controls (see Fig. 2a and Table 2).

\section{CSF levels of SMOC2 and YKL-40 were increased in $A \beta$ - positive, cognitively normal individuals}

Two proteins were increased in the CSF of $A \beta+\operatorname{cog}$ nitively normal $(\mathrm{CN})$ individuals, including SMOC2 $\left(d=0.19 ; q=9.01 \times 10^{-5}\right)$, which was also increased in the CSF of A $\beta+\mathrm{MCI}$ patients $(d=0.29 ; q=1.16 \times$ $\left.10^{-5}\right)$ and AD-dementia patients $(d=0.28 ; q=1.09 \times$ $\left.10^{-10}\right)$, and YKL-40 $(d=0.13 ; q=0.007)$, which was also increased in the CSF of AD-dementia patients $\left(d=0.17 ; q=1.19 \times 10^{-5}\right.$; see Fig. $1 \mathrm{a}$ and Table 2$)$.

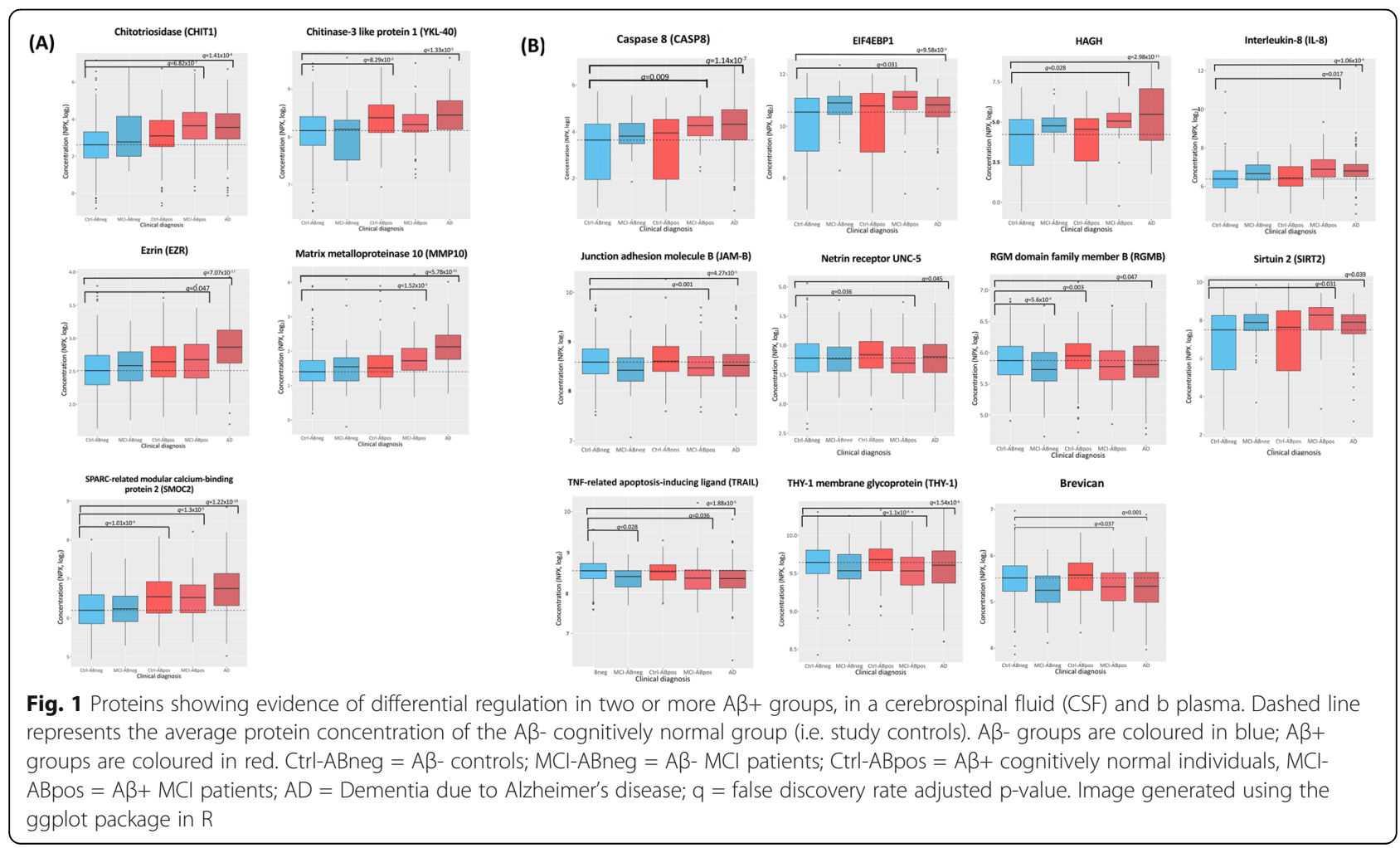


Table 2 Demographic and clinical data for the Memory Malmö 'discovery' cohort

\begin{tabular}{|c|c|c|c|c|c|c|c|}
\hline \multirow[b]{2}{*}{ Protein name } & \multicolumn{7}{|c|}{ Alzheimer's dementia patients vs. $A \beta$ - controls } \\
\hline & \begin{tabular}{|l|} 
Protein \\
abbreviation
\end{tabular} & $\begin{array}{l}\text { CSF } \\
\text { Fold change }\end{array}$ & $\begin{array}{l}\text { CSF } \\
\text { Std. error }\end{array}$ & $\begin{array}{l}C S F \\
\text { a-value }\end{array}$ & \begin{tabular}{|l|l|} 
Plasma \\
Fold change
\end{tabular} & $\begin{array}{l}\text { Plasma } \\
\text { Sta. error }\end{array}$ & $\begin{array}{l}\text { Plasma } \\
\text { quvalue }\end{array}$ \\
\hline Chitinase 1 (chitotriosidase) & CHIT12 & 0.76 & 0.12 & $1.26 \times 10^{-8}$ & -0.26 & 0.16 & 1 \\
\hline Matrix metalloproteinase $10^{2}$ & MMP-10 & 0.54 & 0.04 & $5.2 \times 10^{-31}$ & -0.04 & 0.05 & 1 \\
\hline $\begin{array}{l}\text { Disintegrin and metalloproteinase } \\
\text { domain- containing protetin } 22\end{array}$ & ADAM22 & 0.32 & 0.03 & $9.24 \times 10^{-20}$ & -0.07 & 0.05 & 1 \\
\hline $\begin{array}{l}\text { SPARC-related modular calcium- } \\
\text { binding protein } 2^{24}\end{array}$ & SMOC2 $2^{2,4}$ & 0.28 & 0.04 & $1.09 \times 10^{-10}$ & -0.18 & 0.04 & 0.002 \\
\hline \begin{tabular}{|l|l} 
Eriin & \\
\end{tabular} & $\mathrm{EZR}^{2}$ & 0.24 & 0.03 & $6.34 \times 10^{-17}$ & 0.00 & 0.03 & 1 \\
\hline Osteoprotegerin ${ }^{3}$ & $\mathrm{OPG}^{3}$ & 0.20 & 0.03 & $3.75 \times 10^{-8}$ & 0.05 & 0.03 & 1 \\
\hline $\begin{array}{l}\text { Eukaryotic translation initiation factor } \\
\text { 4E- binding protein } 1\end{array}$ & EIF4EBP1* & 0.19 & 0.03 & $9.07 \times 10^{-8}$ & 0.39 & 0.09 & 0.009 \\
\hline Chitinase-3-like protein $1^{4}$ & CHISL1 (YKL-40) & 0.17 & 0.03 & $1.19 \times 10^{-5}$ & 0.12 & 0.09 & 1 \\
\hline C-C motif chemokine 3 & $\mathrm{CCL} 3$ & 0.17 & 0.03 & $3.8 \times 10^{-5}$ & -0.03 & 0.06 & 1 \\
\hline Caspase 8 & CASP8* & 0.16 & 0.02 & $2.2 \times 10^{-14}$ & 0.67 & 0.11 & $1.1 \times 10^{-7}$ \\
\hline STAM-binding protein & STAMBP & 0.13 & 0.02 & $2.38 \times 10^{-11}$ & -0.09 & 0.12 & 1 \\
\hline $\begin{array}{l}\text { Tumor necrosis factor receptor } \\
\text { superfamily member } 12 \mathrm{~A}\end{array}$ & TNFRSF12A & 0.12 & 0.02 & $3.7 \times 10^{-5}$ & 0.05 & 0.04 & 1 \\
\hline \begin{tabular}{|l|l} 
Tissue factor pathway inhibitior \\
\end{tabular} & TFPI & 0.12 & 0.03 & 0.002 & 0.02 & 0.03 & 1 \\
\hline Junction achesion molecule B & JAM-B* & -0.05 & 0.01 & 0.044 & -0.17 & 0.03 & $4.11 \times 10^{-5}$ \\
\hline Epidermal growth factor receptor & EGFR & -0.06 & 0.02 & 0.04 & -0.07 & 0.03 & 1 \\
\hline Matrix metalloproteinase 2 & MMP-2 & -0.07 & 0.02 & 0.038 & -0.07 & 0.04 & 1 \\
\hline CD166 antigen & ALCAM & -0.07 & 0.02 & 0.027 & -0.05 & 0.03 & 1 \\
\hline Netrin receptor UNC5C & UNC55" & -0.09 & 0.02 & 0.026 & -0.11 & 0.03 & 0.043 \\
\hline LDL receptor & LDLreceptor* & -0.09 & 0.02 & 0.025 & -0.22 & 0.06 & 0.016 \\
\hline RGM domain family member $\mathrm{B}^{3}$ & RGMB"s & -0.10 & 0.02 & $5.74 \times 10^{-5}$ & -0.12 & 0.03 & 0.045 \\
\hline Interlukin 17 receptor alpha & IL-17RA & -0.12 & 0.03 & 0.024 & -0.14 & 0.05 & 1 \\
\hline Cadherin-6 & $\mathrm{CDH} 6$ & -0.12 & 0.03 & 0.0027 & 0.04 & 0.02 & 1 \\
\hline Tissue-type plasminogen activator & $\operatorname{tPA}^{*}$ & -0.12 & 0.02 & 0.0001 & -0.56 & 0.09 & $1.94 \times 10^{-7}$ \\
\hline $\begin{array}{l}\text { TNF-related apoptosis-inducing } \\
\text { ligand }\end{array}$ & TRAL: & -0.13 & 0.02 & $3.64 \times 10^{-7}$ & -0.17 & 0.03 & $1.81 \times 10^{-5}$ \\
\hline Vascular endothelial growth factor $\mathrm{A}$ & VEGFA & -0.13 & 0.02 & $3.99 \times 10^{-6}$ & -0.12 & 0.07 & 1 \\
\hline OX-2 membrane glycoprotein & CD200 & -0.14 & 0.03 & $6.82 \times 10^{-6}$ & -0.04 & 0.04 & 1 \\
\hline $\begin{array}{l}\text { Insulin-like growth factor-binding } \\
\text { protein } 7\end{array}$ & IGFBP-7 & -0.18 & 0.04 & 0.009 & -0.06 & 0.04 & 1 \\
\hline Fibroblast growth factor 19 & FGF-19 & -0.18 & 0.05 & 0.009 & -0.04 & 0.09 & 1 \\
\hline Kynureninase & KYNU* & -0.19 & 0.04 & 0.0007 & -0.22 & 0.06 & 0.034 \\
\hline $\begin{array}{l}\text { Tyrosine-protein phosphatase non- } \\
\text { receptor type substrate } 1\end{array}$ & SHPS-1 & -0.20 & 0.05 & 0.017 & -0.08 & 0.05 & 1 \\
\hline C-C molit chemokine 19 & CCL19 & -0.30 & 0.06 & $5.86 \times 10^{-5}$ & -0.06 & 0.07 & 1 \\
\hline NKG2D ligand 2 & N2DL2 & -0.34 & 0.05 & $1.74 \times 10^{-3}$ & -0.09 & 0.04 & 1 \\
\hline \multicolumn{8}{|l|}{$A \beta+$ MCI pationts vs. $A \beta$ - controls } \\
\hline Protein name & $\begin{array}{l}\text { Protein } \\
\text { abbreviation }\end{array}$ & $\begin{array}{l}\text { CSF } \\
\text { Fold change }\end{array}$ & $\begin{array}{l}\text { CSF } \\
\text { Std. error }\end{array}$ & $\begin{array}{l}\text { CSF } \\
\text { q.value }\end{array}$ & $\begin{array}{l}\text { Plasma } \\
\text { Fold change }\end{array}$ & $\begin{array}{l}\text { Plasma } \\
\text { Std. error }\end{array}$ & $\begin{array}{l}\text { Plasma } \\
\text { q.value }\end{array}$ \\
\hline 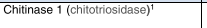 & CHIT1 & 0.95 & 0.16 & $6.08 \times 10^{-7}$ & .0 .04 & 0.22 & 1 \\
\hline Matrix metalloproteinase $10^{2}$ & MMP10 ${ }^{2}$ & 0.32 & 0.06 & $1.16 \times 10^{-5}$ & -0.02 & 0.08 & 1 \\
\hline $\begin{array}{l}\text { SPARC-related modular calcium- } \\
\text { binding protein } 2^{1,4}\end{array}$ & smoc2 $2^{1,4}$ & 0.29 & 0.05 & $1.16 \times 10^{-5}$ & -0.17 & 0.05 & 0.35 \\
\hline Tumor necrosis factor receptor 2 & TNF-R2 & 0.19 & 0.04 & $3.03 \times 10^{-5}$ & -0.15 & 0.07 & 1 \\
\hline Ezrin'1 & EZR' & 0.13 & 0.04 & 0.042 & 0.03 & 0.04 & 1 \\
\hline Osteopontin & OPN & 0.11 & 0.03 & 0.028 & 0.01 & 0.07 & 1 \\
\hline GDNF family receptor alpha-1 & GFR-alpha-1 & 0.10 & 0.03 & 0.034 & -0.04 & 0.05 & 1 \\
\hline \multicolumn{8}{|l|}{$\overline{A \beta}$-MGI pationts vs. $A \beta$-controls } \\
\hline Protein name & \begin{tabular}{|l} 
Protein \\
abbreviation
\end{tabular} & $\begin{array}{l}\text { CSF } \\
\text { Fold change }\end{array}$ & $\begin{array}{l}C S F \\
\text { Std. error }\end{array}$ & \begin{tabular}{|l|l|}
$C$ SF \\
q-value
\end{tabular} & $\begin{array}{l}\text { Plasma } \\
\text { Fold change }\end{array}$ & \begin{tabular}{|l}
$\begin{array}{l}\text { Plasma } \\
\text { Sta. error }\end{array}$ \\
\end{tabular} & $\begin{array}{l}\text { Plasma } \\
\text { q.value }\end{array}$ \\
\hline Plasminogen activator inhibitior & PAl & 0.24 & 0.05 & 0.002 & 0.36 & 0.13 & 1 \\
\hline Osteoprotegerin' & OPG' & 0.18 & 0.05 & 0.004 & 0.05 & 0.05 & 1 \\
\hline NT-3 growth factor receptor & NTRK3 & -0.14 & 0.04 & 0.028 & -0.09 & 0.05 & 1 \\
\hline RGM domain family member $\mathrm{B}^{1}$ & RGMB*1 & -0.16 & 0.03 & 0.0007 & .0 .25 & 0.05 & $2.16 \times 10^{-6}$ \\
\hline Contactin-5 & $\begin{array}{ll}\text { CNTN5 } \\
\end{array}$ & -0.17 & 0.05 & 0.04 & -0.14 & 0.07 & 1 \\
\hline Glypican-5 & GCP5 & -0.20 & 0.05 & 0.032 & .0 .08 & 0.16 & 1 \\
\hline Draxin & DRAXIN & -0.20 & 0.05 & 0.01 & .0 .21 & 0.09 & 1 \\
\hline Roundabout homolog 2 & ROBO2 & -0.23 & 0.06 & 0.019 & .0 .18 & 0.07 & 1 \\
\hline \multicolumn{8}{|l|}{$A \beta+$ controls vs. $A \beta$-controls } \\
\hline Protein name & $\begin{array}{l}\text { Protein } \\
\text { abbreviation }\end{array}$ & $\begin{array}{l}\text { CSF } \\
\text { Fold change }\end{array}$ & $\begin{array}{l}C S F \\
\text { SSta error }\end{array}$ & \begin{tabular}{|l|l|} 
CSF \\
qvalue
\end{tabular} & \begin{tabular}{|l} 
Plasma \\
Fold change
\end{tabular} & $\begin{array}{l}\text { Plasma } \\
\text { Std. orror }\end{array}$ & $\begin{array}{l}\text { Plasma } \\
\text { q.value }\end{array}$ \\
\hline $\begin{array}{l}\text { SPARC-related modular calclium-binding } \\
\text { protein } 2^{2}\end{array}$ & SMOC2 $^{2}$ & 0.19 & 0.04 & $9.01 \times 10^{-5}$ & -0.02 & 0.04 & 1 \\
\hline Chitinase-3-like protein 1 ' & $\begin{array}{|ll|}\text { CHI3L1 } & (\text { YKL- } \\
40)^{\prime} & \end{array}$ & 0.13 & 0.03 & 0.007 & 0.04 & 0.08 & 1 \\
\hline
\end{tabular}

Red text with asterisk ${ }^{*}=$ Protein is differentially regulated in both plasma and CSF

${ }^{1}$ Protein is also differentially regulated in AD-dementia patients

${ }^{2}$ Protein is also differentially regulated in $A B+M C l$ patients

${ }^{3}$ Protein is also differentially regulated in $A B-M C l$ patients

${ }^{4}$ Protein is also differentially regulated in $\mathrm{AB}+\mathrm{CN}$ elderly individuals

CSF levels of OPG were increased, and RGMB were decreased, in $A D$ and $A \beta$-negative $\mathrm{MCl}$

Compared to $A \beta-C N$, CSF concentrations of osteoprotegerin (OPG) were significantly increased in both
A $\beta$ - MCI patients $(d=0.23 ; q=0.004)$ and patients with $\operatorname{AD}\left(d=0.2 ; q=3.75 \times 10^{-8}\right.$; see Fig. $1 \mathrm{a}$ and Table 2). A $\beta$ - MCI patients also showed significant decreases of repulsive guidance molecule $B$ (RGMB; 


\section{(A) Cerebrospinal fluid}
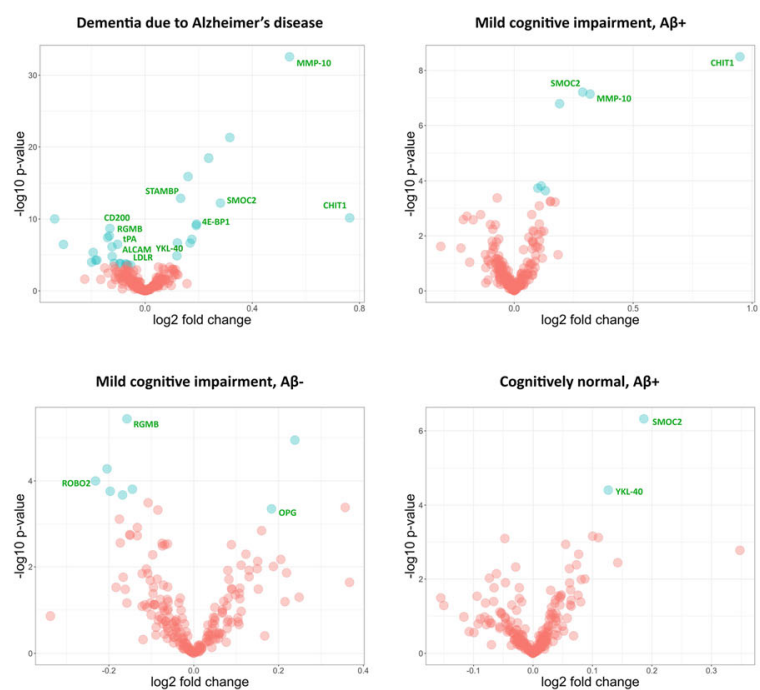

(B) Plasma
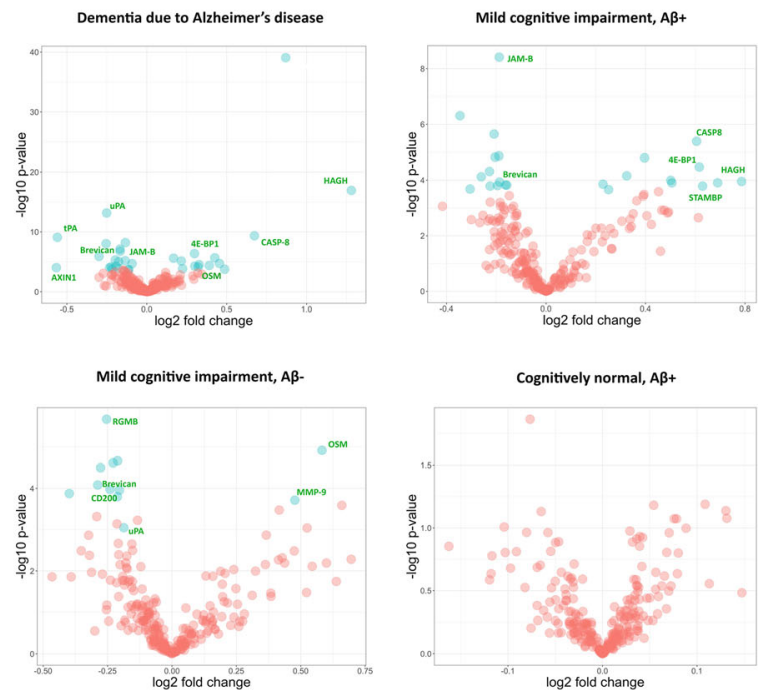

Fig. 2 Volcano plots illustrating the $\log _{2}$-transformed fold change and - $\log _{10}$-transformed $p$-value (uncorrected) for all proteins assessed in a cerebrospinal fluid and $\mathbf{b}$ plasma. Proteins showing evidence of differential regulation after adjustment for false discovery rate (FDR) are denoted in blue. Proteins showing evidence of differential regulation in two or more patient groups, and/or showing replicated evidence of differential regulation in the Memory Lund replication sample, are noted in green text

$d=-0.16 ; q=0.0007)$, which was decreased in $\mathrm{AD}$ $\left(d=-0.1 ; q=5.74 \times 10^{-5}\right.$; see Fig. $1 \mathrm{a}$ and Table 2$)$. An additional six proteins were differentially regulated in A $\beta$ - MCI patients only (see Fig. 2a and Table 2).

\section{Findings were replicated for eleven proteins in CSF}

Altered levels of 11 CSF proteins, as observed in our primary analysis, were replicated in an independent cohort of 179 individuals. In the replication sample, CHIT1 CSF levels were significantly up-regulated in $\mathrm{A} \beta+\mathrm{MCI}$ patients $\left(d=1.16, p=4.9 \times 10^{-6}\right.$, unadjusted), A $\beta$ - MCI patients ( $d=0.8, p=0.003$, unadjusted), and $\mathrm{A} \beta+\mathrm{CN}$ individuals $\left(d=1.28, p=2.63 \times 10^{-5}\right.$, unadjusted) compared to $\mathrm{A} \beta$ $\mathrm{CN}$. SMOC2 CSF levels were also increased in $\mathrm{A} \beta+\mathrm{MCI}$ patients $\left(d=0.4, p=2 \times 10^{-3}\right.$, unadjusted) and $\mathrm{A} \beta-+\mathrm{CN}$ individuals $\left(d=0.45, p=5 \times 10^{-3}\right.$, unadjusted) compared to $A \beta-C N$. CSF levels of LDL receptor were modestly decreased in $\mathrm{A} \beta+\mathrm{MCI}$ patients $(d=-0.09, p=0.049$, unadjusted) and $\mathrm{A} \beta+\mathrm{CN}$ individuals $(d=-0.14, p=0.007$, unadjusted). CSF levels of CD200 were also modestly decreased in $\mathrm{A} \beta+\mathrm{MCI}$ patients $d=-0.13, p=0.043$, unadjusted) and $\mathrm{A} \beta-\mathrm{MCI}$ patients $(d=-0.15, p=0.03$, unadjusted). Compared to $\mathrm{A} \beta-\mathrm{CN}, \mathrm{A} \beta+\mathrm{MCI}$ patients showed increased CSF levels of MMP-10 $(d=0.32, p=$ 0.008 , unadjusted) and EIF4EBP1 $(d=0.13, p=0.038$, unadjusted), and decreased CSF levels of CD166 antigen (ALCAM; $d=-0.12, p=0.005$, unadjusted). Compared to controls, ROBO2 ( $d=-0.27, p=0.004$, unadjusted) and RGMB protein $(d=-0.11, p=0.049$, unadjusted) were decreased in the CSF of A $\beta$ - MCI patients, whereas tissue plasminogen activator (tPA) was decreased $(d=-0.2, p=$ 0.004 , unadjusted) and STAM-binding protein (STAMBP) was increased $(d=0.09, p=0.03$, unadjusted) in $\mathrm{A} \beta+\mathrm{MCI}$ patients (see Fig. 2a and Additional file 1: Table S7).

\section{Plasma levels of HAGH, SIRT2, CASP8, EIF4EBP1, and IL-8 were increased in $A D$ and $A \beta$-positive $M C I$}

Compared to $A \beta-C N$, five plasma proteins were significantly increased in both $\mathrm{AD}$ and $\mathrm{A} \beta+\mathrm{MCI}$ patients, including HAGH $(d=0.79$ in $\mathrm{A} \beta+\mathrm{MCI} ; d=1.28$ in $\mathrm{AD}$; $q<0.05$ ), sirtuin-2 (SIRT2; $d=0.69$ in A $\beta+\mathrm{MCI} ; d=0.49$ in $\mathrm{AD} ; q<0.05)$, caspase 8 (CASP8; $d=0.62$ in $\mathrm{A} \beta+$ $\mathrm{MCI} ; d=0.67$ in AD; $q<0.01)$, EIF4EBP1 $(d=0.51$ in $\mathrm{A} \beta+\mathrm{MCI} ; d=0.39$ in $\mathrm{AD} ; q<0.05)$, and interleukin-8 (IL-8; $d=0.32$ in $\mathrm{A} \beta+\mathrm{MCI} ; d=0.3$ in $\mathrm{AD} ; q<0.05$; see Fig. $1 \mathrm{~b}$ and Table 3). AD-dementia and A $\beta+$ MCI patients showed additional increases in two distinct sets of six proteins, as detailed in Table 3.

\section{Plasma levels of JAM-B, brevican, THY-1, RGMB, UNC5C and TRAIL were decreased in $A D$ and $A \beta$-positive $M C I$}

$A D$ and $A \beta+M C I$ patients showed decreases in six plasma proteins, including JAM-B $(d=-0.23$ in $\mathrm{A} \beta+$ $\mathrm{MCI} ; d=-0.21$ in $\mathrm{AD} ; q<0.001)$, brevican $(d=-0.2$ in $\mathrm{A} \beta+\mathrm{MCI} ; d=-0.23$ in $\mathrm{AD} ; q<0.05)$, thy- 1 membrane glycoprotein (THY1; $d=-0.19$ in $\mathrm{A} \beta+\mathrm{MCI} ; d=-0.13$ in AD; $\left.q<1 \times 10^{-5}\right)$, RGMB $(d=-0.19$ in $\mathrm{A} \beta+\mathrm{MCI} ; d=$ -0.12 in $\mathrm{AD} ; q<0.05)$, UNC5C $(d=-0.16$ in $\mathrm{A} \beta+\mathrm{MCI}$; $d=-0.11$ in $\mathrm{AD} ; q<0.05)$, and TRAIL $(d=-0.16$ in $\mathrm{A} \beta+\mathrm{MCI} ; d=-0.17$ in AD; $q<0.05)$; see Fig. $1 \mathrm{~b}$ and Table 3. 
Table 3 Differentially regulated proteins in human plasma

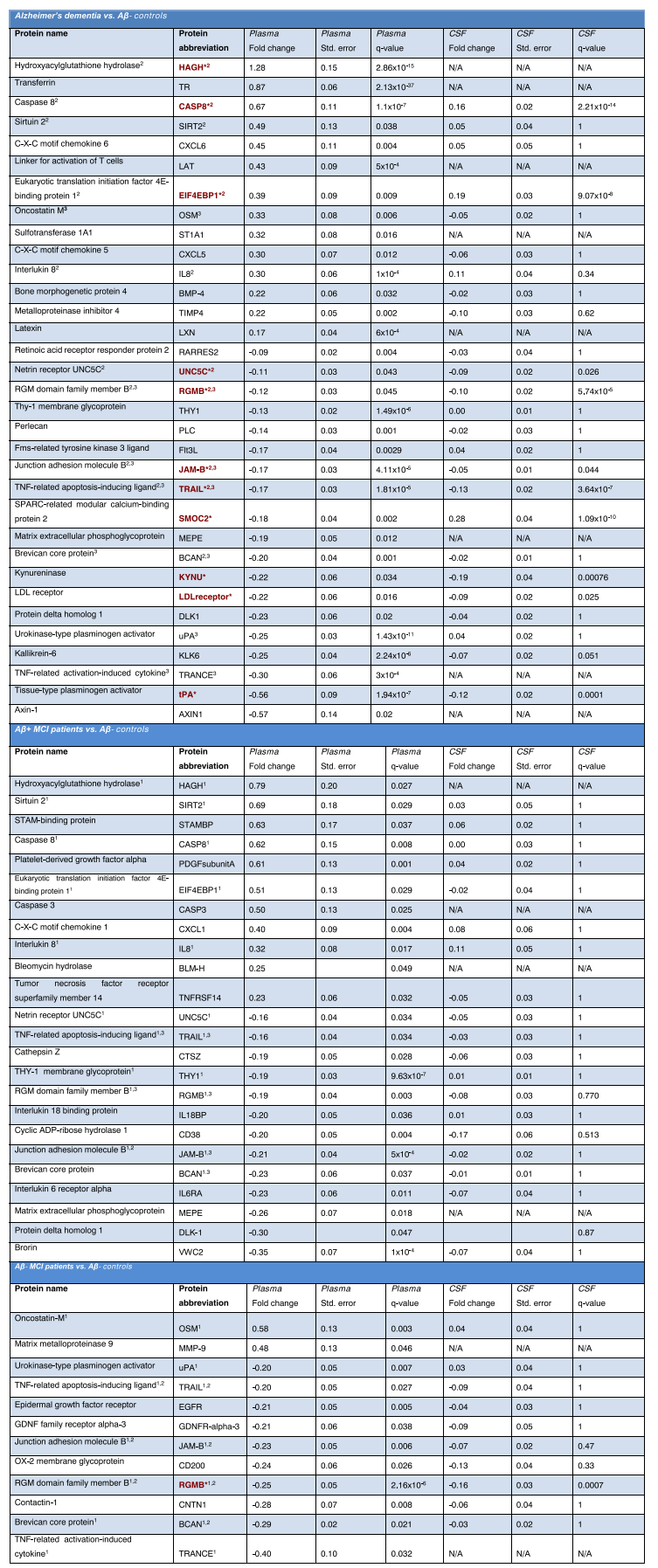

Red text with asterisk ${ }^{*}=$ Protein is differentially regulated in both plasma and CSF

${ }^{1}$ Protein is also differentially regulated in AD-dementia patients

${ }^{2}$ Protein is also differentially regulated in $A B+M C l$ patients

${ }^{3}$ Protein is also differentially regulated in $A B-M C l$ patients

An additional 13 proteins were decreased in $\mathrm{AD}$ patients only, and seven proteins were decreased in $A \beta+$ MCI patients only, when compared to A $\beta$ - controls (see Table 3).
The $A \beta+C N$ group did not show any significant differential regulation of proteins in plasma when compared to $\mathrm{A} \beta-\mathrm{CN}(q>0.05)$. 
Plasma levels of OSM were increased, and RGMB, JAM-B, TRAIL, TRANCE and brevican were decreased, in AD and $A \beta$-negative $\mathrm{MCI}$

Compared to $A \beta-C N, A \beta-M C I$ patients showed increased levels of oncostatin M (OSM; $d=0.58 ; q=0.003)$ in plasma, which were also significantly increased in $\mathrm{AD}$ $(d=0.33 ; q=0.006$; see Table 3$)$.

$\mathrm{AD}, \mathrm{A} \beta+\mathrm{MCI}$, and $\mathrm{A} \beta-\mathrm{MCI}$ patients all showed decreases of three proteins in plasma, including RGMB $(d=-0.25$ in $\mathrm{A} \beta-\mathrm{MCI} ; d=-0.19$ in $\mathrm{A} \beta+\mathrm{MCI} ; d=-$ 0.12 in $\mathrm{AD} ; q<0.05)$, JAM-B $(d=-0.23$ in $\mathrm{A} \beta$ - MCI; $d=-0.21$ in $\mathrm{A} \beta+\mathrm{MCI} ; d=-0.17$ in $\mathrm{AD} ; q<0.001)$, TRAIL $(d=-0.2$ in $\mathrm{A} \beta-\mathrm{MCI} ; d=-0.16$ in $\mathrm{A} \beta+\mathrm{MCI}$; $d=-0.17$ in $\mathrm{AD} ; q<0.05)$.

Two proteins were decreased in both $A \beta-M C I$ and $\mathrm{AD}$ compared to $\mathrm{A} \beta$ - controls, including TNF-related activation-induced cytokine (TRANCE; $d=-0.4$ in A $\beta$ MCI; $d=-0.3$ in AD; $q<0.05)$ and brevican $(d=-0.29$ in $\mathrm{A} \beta$ - MCI; $d=-0.2$ in AD; $q<0.05)$; see Fig. $2 \mathrm{~b}$ and Table 3.

\section{Findings were replicated for six proteins in plasma} In an independent sample of 179 individuals, we observed differential regulation of seven proteins that were also differentially regulated in our primary analysis. Plasma levels of OSM were increased in A $\beta+\mathrm{MCI}$ patients $(d=0.37, p=0.035$, unadjusted) and $\mathrm{A} \beta$ - MCI patients $(d=0.56, p=0.002$, unadjusted) compared to $\mathrm{A} \beta$ $\mathrm{CN}$. Plasma MMP-9 levels were increased in A $\beta+\mathrm{MCI}$ patients $(d=0.41, p=0.01$, unadjusted) and $\mathrm{A} \beta$ - MCI patients ( $d=0.55, p=0.003$, unadjusted) compared to $\mathrm{A} \beta$ $\mathrm{CN}$. Increased levels of HAGH $(d=0.6, p=0.0061$, unadjusted) and CD200 ( $d=0.15, p=0.02$, unadjusted $)$ were also observed in $A \beta+C N$ compared to $A \beta-C N$. Pronounced decreases of AXIN1 were observed in the plasma of $\mathrm{A} \beta+\mathrm{MCI}$ patients $(d=0.51, p=0.02$, unadjusted), A $\beta$ - MCI patients $(d=-0.77, p=0.002$, unadjusted), and $\mathrm{A} \beta+\mathrm{CN}$ individuals $(d=-0.77, p=0.005$, unadjusted) compared to $A \beta-C N$. Finally, plasma levels of urokinase-type plasminogen activator (uPA) were decreased in $\mathrm{A} \beta+\mathrm{MCI}$ patients $(d=-0.14, p=0.02$, unadjusted), $\mathrm{A} \beta-\mathrm{MCI}$ patients $(d=-0.16, p=0.043$, unadjusted), and $\mathrm{A} \beta+\mathrm{CN}$ individuals $(d=-0.14, p=$ 0.044 , unadjusted) compared to $\mathrm{A} \beta-\mathrm{CN}$ (see Fig. $2 \mathrm{~b}$ and Additional file 1: Table S8).

\section{CSF levels of MMP-10 and YKL-40 negatively associated with baseline cortical thickness levels}

Quality inspection identified four MCI patients and one control with segmentation errors; thus, 410 participants were included in the final MRI analysis.

AD-signature cortical thickness [17] was negatively associated with four proteins in CSF, including MMP-10 and YKL-40 $(q<0.05)$, both of which were differentially regulated in the cross-sectional analyses, and two proteins in plasma, including elafin and lymphotoxin-beta receptor $(q<0.01$; Additional file 1: Table S9). Baseline hippocampal volume was not significantly associated with protein levels in plasma or CSF $(q>0.05)$.

\section{Multiple differentially regulated CSF and plasma proteins associated with cognitive performance}

Baseline CDR-SB scores were significantly associated with levels of sixteen proteins in CSF, including SMOC2, IL8, MMP-10, CCL3, TNF-R2, ezrin, RGMB and OPN, all of which were differential regulated in our univariate analysis $(q<0.05$; Additional file 1: Table S10). Baseline CDR-SB score was also associated with concentrations of eight proteins in plasma, including positive associations with IL-8 and TIMP4, and negative associations with JAM-B, THY1 and latexin, all of which were differentially regulated in our univariate analysis $(q<0.05$; Additional file 1: Table S11). Baseline MMSE scores negatively associated with levels of four proteins in plasma, including IL8 and PDF subunit alpha $(-0.1<$ $b<-0.05 ; q<0.05)$, and positively associated with levels of fifteen proteins in plasma, including THY1, RGMB, brevican, brorin, kallikrein-6, bone morphogenetic protein 4, TRANCE, and delta homolog $1(q<0.05$; Additional file 1: Tables S12-S13). In CSF, MMP-10, OPN and TNF-R2 were nominally associated with baseline MMSE score, but did not survive FDR adjustment $(q>$ 0.05).

\section{Approximately half of CSF proteins correlated modestly with their analogs in plasma}

Overall, the strongest protein-protein correlations were observed within fluids, as illustrated in Fig. 3 and Additional file 1: Table S14. Between fluids, moderate-tostrong, positive correlations were observed for 14 proteins in CSF and their corresponding analogs in plasma, including CHIT1, which was significantly up-regulated in our primary univariate analysis of patients with $\mathrm{AD}$ dementia and $\mathrm{A} \beta+\mathrm{MCI}$ versus $\mathrm{A} \beta$ - controls $(0.5<r<$ $\left.0.73 ; q<1 \times 10^{-61}\right)$. Weak-to-modest positive correlations were observed across an additional 123 proteins in CSF and their analogs in plasma, including 35 proteins showing evidence of differential regulation in our univariate cross-sectional analyses $(0.08<r<0.49 ; q<0.05$; Additional file 1: Table S14).

\section{Multivariate modeling predicted early AD with high accuracy in CSF}

A series of multivariate LASSO regression models produced high predictive accuracy estimates in CSF for AD dementia, in a model that included 36 biomarkers ( $\mathrm{AUC}=0.95,95 \% ; \mathrm{CI}=0.9-0.99$ ), and for $\mathrm{A} \beta+\mathrm{MCI}$, in a model that included 43 biomarkers and gender $(\mathrm{AUC}=$ 


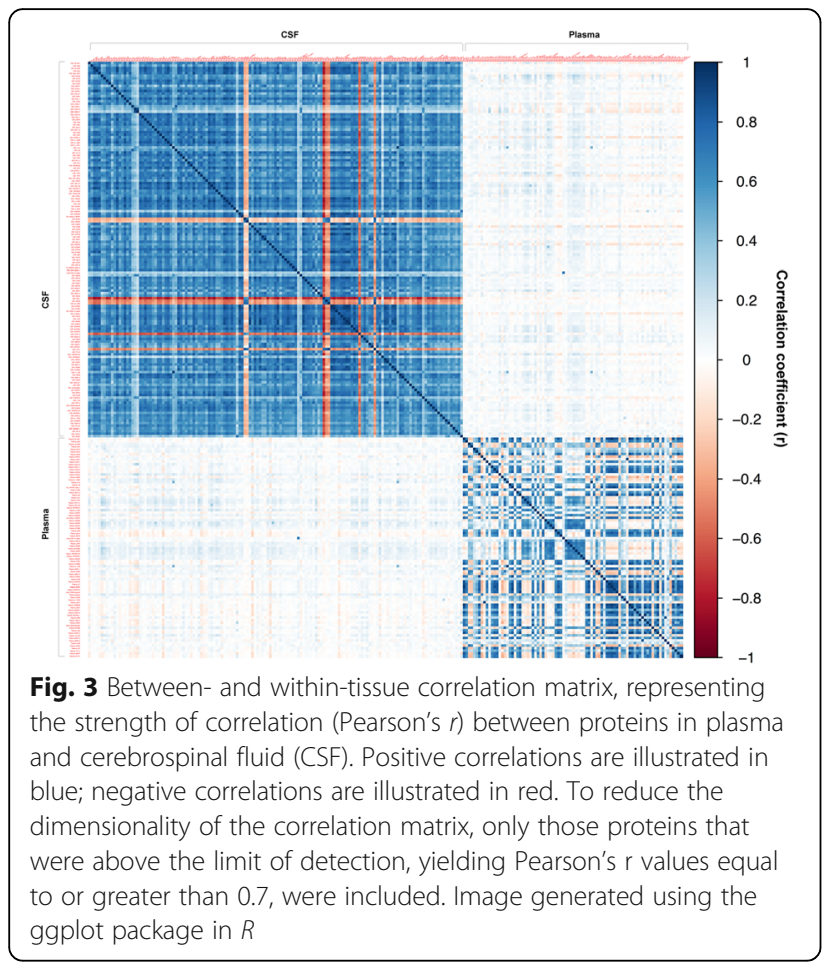

0.92; $95 \% \mathrm{CI}=0.80-0.98)$. AUCs for CSF models were non-significant for $\mathrm{A} \beta-\mathrm{MCI} \quad(\mathrm{AUC}=0.78,95 \% \mathrm{CI}=$ 0.46-0.98), and low for $\mathrm{A} \beta+\mathrm{CN}$, in a model that included 14 biomarkers and gender $(\mathrm{AUC}=0.64,95 \% \mathrm{CI}=$ 0.57-0.7; Additional file 1: Table S2).

\section{Multivariate modeling predicted AD with high accuracy, and $\mathrm{MCl}$ with moderate accuracy, in plasma}

In plasma, multivariate regression produced high AUCs for $\mathrm{AD}$ dementia, in a model that included 74 biomarkers and age (AUC $=0.94,95 \% \mathrm{CI}=0.87-0.98$ ). Predictive accuracy was moderate for $\mathrm{A} \beta+\mathrm{MCI}$, in a model that included 53 biomarkers and age $(\mathrm{AUC}=0.78,95 \%$ $\mathrm{CI}=0.68-0.87$; see Additional file 1: Table S3). The plasma models were not significant for $\mathrm{A} \beta$ - MCI (AUC = $0.76,95 \% \mathrm{CI}=0.47-0.92)$ or $\mathrm{A} \beta+\mathrm{CN}(\mathrm{AUC}=0.58,95 \%$ $\mathrm{CI}=0.47-0.72)$.

\section{Discussion}

In one of the broadest multiplex proteomics studies of dementia conducted to date, we identified a series of significant alterations across plasma and CSF, implicating multiple proteins involved in regulation of the inflammatory response, apoptosis, endocytosis, leukocyte proliferation, and other biological processes believed to be downstream of, and potentially orthogonal to, $A \beta$ and tau deposition. A subset of proteins collectively discriminated individuals with $\mathrm{AD}$ dementia from healthy controls with $95 \%$ predictive accuracy in CSF, and 94\% accuracy in plasma, representing an improvement over prior multiplex panels [13, 16, 36, 42, 43]. With the exceptions of YKL-40 [1, 11, 18] and CHIT1 [27] in CSF, and MMP-9 [7] in blood, our findings highlight a set of relatively unexplored candidate biomarkers of neurodegeneration, warranting further validation in independent disease cohorts using targeted proteomic assays.

Our findings highlight the roles of several functionally pleiotropic proteins in AD, such as CASP8, which was increased in the plasma and CSF of AD-dementia patients, and in the plasma of A $\beta+$ MCI patients. CASP8 is involved in synaptic plasticity, amyloid processing, memory, and regulation of microglial pro-inflammatory activation [60]. The CASP8 gene has shown a significant rare variant burden association with $\mathrm{AD}$ susceptibility [46], and prior immunohistochemical analyses have revealed activation of CASP8 in AD hippocampal tissue [47]. Caspase inhibition has been proposed as a mechanism to promote neuronal survival [49], and may be a beneficial therapeutic strategy for AD.

Similarly, JAM-B, a protein involved in synaptic adhesion, lymphocyte transendothelial migration [21], and vascular inflammation [59], was down-regulated in the plasma and CSF of AD patients and the plasma of MCI patients compared with cognitively normal $A \beta$ - controls. In plasma, JAM-B levels negatively associated with baseline CDR-SB scores. Polymorphisms in or near the JAM2 gene have shown suggestive associations with cognitive performance [34], postmortem $A \beta$ load [51], and longitudinal changes in amyloid plaque burden on PET [44].

CSF concentrations of MMP-10 were elevated in $\mathrm{A} \beta+\mathrm{MCI}$ and $\mathrm{AD}$ patients, positively correlated with cognitive performance, and negatively associated with AD-signature cortical thickness. Other matrix metalloproteinase-related proteins, including MMP-9, TIMP-4, and ADAM22, were also up-regulated in AD. These findings highlight the complex pathophysiological role of endopeptidases in $\mathrm{AD}$, potentially via direct degradation of $A \beta$ deposits [32] or indirect mediation of A $\beta$-induced blood-CSF barrier dysfunction [6]. Transferrin receptor, which facilitates brain iron uptake, was also significantly increased in the plasma of $\mathrm{AD}$ patients, implicating elevated brain iron levels, potentially via blood-brain barrier (BBB) breakdown, in disease pathophysiology [54]. Further investigation of the role of metalloproteinases, endothelial proteins and adhesion molecules, particularly as they relate to meningeal lymphatics, BBB function and iron levels in AD [54], may facilitate novel therapeutic target discovery.

In the CSF and plasma of AD patients, we found decreased concentrations of tPA, a blood clotting enzyme which co-localizes with amyloid-rich regions and phosphorylated tau in post-mortem AD brains [30], and has 
been linked to accelerated $A \beta$ degradation in-vivo [37]. In $\mathrm{AD}$ plasma, we found decreased levels of another plasminogen activator, uPA, which has been associated with inhibition of $A \beta$ neurotoxicity and fibrillogenesis [56] and recovery after axonal injury [31].

Other notable proteins that showed evidence of differential regulation in $\mathrm{AD}$ compared to healthy elderly individuals included CD200, a glycoprotein previously associated with enhanced in-vivo and in-vitro amyloid phagocytosis [57], UNC5, an axonal guidance protein receptor which has previously shown genetic links to familial, late-onset $\mathrm{AD}$ via increased susceptibility to neuronal cell death [61], and SMOC2, a member of the SPARC protein family, which is involved in microgliosis and functional recovery after cortical ischemia [24], and was significantly associated with cognitive performance in our study. We also observed profound increases of HAGH, also known as glyoxalase II, in plasma, reemphasizing the potential role of advanced glycation end products in neurodegeneration [23, 63].

Our study highlights the changes and potential contributions of several chemokines (CXCL1, CCL3, CXCL5, CXCL6, CCL3, CCL19), interleukins (IL8, IL6-RA, IL18BP), and other immune markers (OSM, ALCAM, OPG, CHIT1, YKL-40, STAMBP, MMP-9, MMP-10) in the prodromal and dementia phases of AD. YKL-40, a chitinase expressed by astrocytes and microglia in the CNS [8], was increased in the CSF of $A \beta+C N$ individuals and patients with $\mathrm{AD}$, and negatively associated with thickness measures in $\mathrm{AD}$-vulnerable brain regions, replicating prior findings [2] and reemphasizing similar findings from the same cohort, using a standard ELISA assay [19]. However, elevations of YKL-40 in CSF were modest compared with prior investigations $[1,11,18]$ and were negligible in plasma, indicating limited diagnostic utility of this biomarker in isolation [27]. CHIT1, another putative marker of microglial activation, showed more pronounced elevations in the CSF of $\mathrm{A} \beta+\mathrm{MCI}$ and $\mathrm{AD}$ patients, supporting prior observations of up-regulated CHIT1 in progressive brain illnesses $[53,58]$, and warranting further investigation of the role of chitinases in immune response and neurodegeneration.

Compared with $\mathrm{A} \beta-\mathrm{CNs}$, MCI patients without evidence of pathological CSF A $\beta$ showed significant differential regulation of OPG, RGMB and $\mathrm{ROBO} 2$ protein in CSF, and differential regulation of multiple proteins in plasma, including brevican. OPG, RGMB, and ROBO2 have been implicated in CNS development, axonal growth, and recovery after nerve injury [15, 25, 50], whereas upregulation of brevican has been observed in the CNS during the consolidation of long-term memories [35]. Thus, dysregulation of these proteins in $A \beta$ MCI may reflect broader mechanisms involved in neurodegeneration, potentially unrelated to $A \beta$ pathology.
Conversely, certain proteins, dysregulated when $A \beta+$ patients were compared to $A \beta$ - controls, may reflect the presence of $A \beta$ deposits rather than a specific diagnosis of $\mathrm{AD}$ or MCI. To address this possibility, we conducted a series of supplementary analyses, as detailed in Additional file 1: Note 1. These analyses revealed that, with the exceptions of CHIT1, YKL-40 and SMOC2 in CSF, most differentially regulated proteins identified in $A \beta+$ patients may represent markers of disease diagnosis, rather than $A \beta$ deposition alone, as they showed similar patterns of differential regulation when $A \beta+$ groups were compared with one another directly (see Additional file 1 : Tables S23-S32).

Some differentially regulated proteins may reflect the influences of coexisting pathologies in $\mathrm{AD}$, such as Lewy body inclusions or TDP-43 aggregates. To test this hypothesis, we conducted supplementary analyses in a small, independent cohort of $A \beta$ - healthy elderly individuals compared with $A \beta$ - patients with Parkinson's disease (PD), multiple system atrophy (MSA), and progressive supranuclear palsy (PSP; see Additional file 1: Note 1). This analysis indicated that MMP-10, STAMBP, LDL receptor, and EIF4EBP1 likely represent diseasespecific biomarkers of AD, whereas CHIT1, ALCAM, CD200, OPG, ROBO2, and RGMB may serve as broader neurodegeneration biomarkers, potentially influenced by coexisting pathologies beyond $\mathrm{A} \beta$ - and tau (Additional file 1: Tables S33-S38). Further studies of patients with Lewy body dementia, frontotemporal dementia, and other neurodegenerative illnesses are strongly recommended to help validate these findings.

Despite its scale, our study has limitations. Many differentially regulated proteins yielded small-to-modest effect sizes $(0.05<d<0.4)$, and the functions of some proteins demonstrating AD-related changes are not fully understood. Also, given the study's cross-sectional design, we could not investigate the precise temporal dynamics of important biological processes such as innate immunity in AD. Future investigations will combine longitudinal plasma and CSF measurements with genomewide genotyping to disentangle causal from consequential biomarkers, and to map the development of protein biomarkers throughout the progression of disease. Additionally, the Olink ${ }^{\mathrm{Tm}}$ PEA technology takes advantage of unique tags and polymerase chain reaction to measure up to 92 proteins in parallel, including many lowexpressing analytes typically undetected using traditional multiplex assays. The technology therefore represents a relatively focused screen, whereby protein levels are reported as normalized protein concentration (NPX). Prospective experiments should combine more unbiased proteomics approaches (such as mass spectrometry) with targeted assays (such as enzyme-linked immunoabsorbance assays, single molecule arrays, or 
customized Olink $^{\mathrm{m}}$ panels), reporting results as absolute concentrations.

Finally, while we identified subsets of proteins that accurately discriminated $\mathrm{MCI}$ and $\mathrm{AD}$ patients from elderly controls, further work is required to identify a suitable selection of biomarkers for very early detection of cognitive impairment, prior to the presentation of overt clinical symptoms. Replication studies in independent cohorts, complemented by larger multiplex proteomics panels, genetic risk scores, advanced neuroimaging, neuropsychological assessments, and post-mortem expression studies will help characterize early contributors towards longitudinal cognitive decline in $\mathrm{AD}$ [33].

\section{Conclusion}

In conclusion, we have implicated multiple markers of neuroinflammation, cerebrovascular dysfunction, apoptosis, and other CNS processes in the preclinical, prodromal, and dementia phases of AD. Approximately one third of proteins successfully assayed in CSF significantly correlated with their analogs in plasma, and several differentially regulated proteins were associated with cortical atrophy and cognitive performance. These findings inform our understanding of AD biology, and indicate that blood-based biomarker panels may facilitate $\mathrm{AD}$ diagnosis, pending further refinement and validation.

\section{Additional file}

Additional file 1: Supplementary Materials, Part 1: Notes S1-S2, Figures S1-S8, and Tables S1-S6. Supplementary Materials, Part 2: Tables S7-S39. (ZIP $789 \mathrm{~kb})$

\section{Authors' contributions}

Conception and design: $\mathrm{OH}, \mathrm{AM}, \mathrm{CDW}$. Acquisition of data: OH, SJ, ES, NM. Data analysis: CDW, NM, MN, SV, CLH. Interpretation of data: CDW, NM, MN, SV, CLH, SJ, ES, JL, LF, TS, GR, RM, AM, OH. Writing of manuscript: CDW, AM, $\mathrm{OH}$. Review and/or revision of manuscript: CDW, NM, MN, SV, CLH, SJ, ES, JL, LF, TS, GR, RM, AM, OH. PI for the BioFINDER study: OH. All authors read and approved the final manuscript.

\section{Funding}

The study was supported by the European Research Council, the Swedish Research Council, the Knut and Alice Wallenberg foundation, the Marianne and Marcus Wallenberg foundation, the Strategic Research Area MultiPark (Multidisciplinary Research in Parkinson's disease) at Lund University, the Swedish Alzheimer Foundation, the Swedish Brain Foundation, The Parkinson foundation of Sweden, The Parkinson Research Foundation, the Skåne University Hospital Foundation, and the Swedish federal government under the ALF agreement. The study was partially supported by a Digital Data Innovation Fund grant, awarded by Pfizer Worldwide Research \& Development.

\section{Availability of data and materials}

Anonymized data will be shared by request from a qualified academic investigator for the sole purpose of replicating procedures and results presented in the article and as long as data transfer is in agreement with EU legislation on the general data protection regulation and decisions by the Ethical Review Board of Sweden and Region Skåne.

\section{Competing interests}

CDW and GR are employees of Biogen Inc. MN, CH, JL, LF, and AM are employees of Pfizer Worldwide Research \& Development. TS is an employee of Sanofi. CDW, GR, TS, and RM were employed at Pfizer Worldwide Research \& Development during the conduct of this study. $\mathrm{OH}$ has acquired research support (for the institution) from Roche, GE Healthcare, Biogen, AVID Radiopharmaceuticals, Fujirebio, and Euroimmun. In the past 2 years, he has received consultancy/speaker fees (paid to the institution) from Biogen, Roche, and Fujirebio.

\section{Author details}

${ }^{1}$ Research and Early Development (RED), Biogen Inc., Cambridge, MA 02139, USA. ${ }^{2}$ Clinical Memory Research Unit, Department of Clinical Sciences, Lund University, Lund, Sweden. ${ }^{3}$ Wallenberg Center for Molecular Medicine, Lund University, Lund, Sweden. ${ }^{4}$ Pfizer Worldwide Research \& Development, Cambridge, MA 02139, USA. ${ }^{5}$ Department of Medicine, Karolinska Institutet, Vetenskapsvagen 10, 17176 Stockholm, Sweden. ${ }^{6}$ Rare and Neurologic Disease Research, Sanofi Research and Development, Framingham, MA 01701, USA. ${ }^{7}$ CNS Research Solutions LLC, Cambridge, MA 02139, USA.

${ }^{8}$ Memory Clinic, Skåne University Hospital, SE-20502 Malmö, Sweden.

Received: 15 July 2019 Accepted: 24 August 2019

Published online: 06 November 2019

\section{References}

1. Alcolea D, Martínez-Lage P, Sánchez-Juan P, Olazarán J, Antúnez C, Izagirre A et al (2015) Amyloid precursor protein metabolism and inflammation markers in preclinical Alzheimer disease. Neurology 85:626-633

2. Alcolea D, Vilaplana E, Pegueroles J, Montal V, Sánchez-Juan P, GonzálezSuárez A et al (2015) Relationship between cortical thickness and cerebrospinal fluid YKL-40 in predementia stages of Alzheimer's disease. Neurobiol Aging 36:2018-2023

3. Alzheimer's Association, 2017. 2017 Alzheimer's disease facts and figures. Alzheimer's \& Dementia. Elsevier; 2017; 13(4): 325-373

4. Assarsson E, Lundberg M, Holmquist G, Björkesten J, Thorsen SB, Ekman D et al (2014) Homogenous 96-Plex PEA Immunoassay Exhibiting High Sensitivity, Specificity, and Excellent Scalability. PLOS ONE 9:e95192

5. Blennow K (2017) A review of fluid biomarkers for Alzheimer's disease: Moving from CSF to blood. Neurol Ther 6:15-24

6. Brkic M, Balusu S, Van Wonterghem E, Gorlé N, Benilova I, Kremer A et al (2015) Amyloid $\beta$ oligomers disrupt blood-CSF barrier integrity by activating matrix metalloproteinases. J Neurosci Soc Neurosci 35:12766-12778

7. Cai Z-Y, Yan Y, Yan L, Wang F-Y, Huang H, Wang Y-L et al (2007) Serum level of MMP-2, MMP-9 and OX-LDL in Alzheimer's disease with hyperlipoidemia. J Med Coll PLA 22:352-356

8. Cantó E, Tintoré M, Villar LM, Costa C, Nurtdinov R, Álvarez-Cermeño JC et al (2015) Chitinase 3-like 1: prognostic biomarker in clinically isolated syndromes. Brain 138:918-931

9. Cho S-H, Sun B, Zhou Y, Kauppinen TM, Halabisky B, Wes P et al (2011) CX3CR1 protein signaling modulates microglial activation and protects against plaque-independent cognitive deficits in a mouse model of Alzheimer disease. J Biol Chem 286:32713-32722

10. Cook D, Brown D, Alexander R, March R, Morgan P, Satterthwaite G et al (2014) Lessons learned from the fate of AstraZeneca's drug pipeline: a fivedimensional framework. Nat Rev Drug Discov 13(6):419-431

11. Craig-Schapiro R, Perrin RJ, Roe CM, Xiong C, Carter D, Cairns NJ et al (2010) YKL-40: a novel prognostic fluid biomarker for preclinical Alzheimer's disease. Biol Psychiatry 68:903-912

12. Cummings J, Lee G, Mortsdorf T, Ritter A, Zhong K (2017) Alzheimer's disease drug development pipeline: 2017. Alzheimers Dement 3:367-384

13. Doecke JD (2012) Blood-based protein biomarkers for diagnosis of Alzheimer disease. Archives of Neurology American Medical Association 69: 1318-1325

14. Fan Z, Brooks DJ, Okello A, Edison P (2017) An early and late peak in microglial activation in Alzheimer's disease trajectory. Brain 140:792-803

15. Hivert B (2002) Robo1 and Robo2 are Homophilic binding molecules that promote axonal growth. Mol Cell Neurosci 21:534-545

16. Hye A, Riddoch-Contreras J, Baird AL, Ashton NJ, Bazenet C, Leung R et al (2014) Plasma proteins predict conversion to dementia from prodromal disease. Alzheimers Dementia 10:799-807.e2 
17. Jack CR, Wiste HJ, Weigand SD, Knopman DS, Mielke MM, Vemuri P et al (2015) Different definitions of neurodegeneration produce similar amyloid/ neurodegeneration biomarker group findings. Brain 138:3747-3759

18. Janelidze S, Hertze J, Zetterberg H, Waldö ML, Santillo A, Blennow K et al (2015) Cerebrospinal fluid neurogranin and YKL-40 as biomarkers of Alzheimer's disease. Ann Clin Transl Neurol 3:12-20

19. Janelidze S, Mattsson N, Stomrud E, Lindberg O, Palmqvist S, Zetterberg H et al (2018) CSF biomarkers of neuroinflammation and cerebrovascular dysfunction in early Alzheimer disease. Neurology 91:e867-e877

20. Janelidze $\mathrm{S}$, Zetterberg $\mathrm{H}$, Mattsson $\mathrm{N}$, Palmqvist $\mathrm{S}$, Vanderstichele $\mathrm{H}$, Lindberg $O$ et al (2016) CSF a $\beta 42 / a \beta 40$ and a $\beta 42 / a \beta 38$ ratios: better diagnostic markers of Alzheimer disease. Ann Clin Transl Neurol 3:154-165

21. Johnson-Léger CA, Aurrand-Lions M, Beltraminelli N, Fasel N, Imhof BA (2002) Junctional adhesion molecule-2 (JAM-2) promotes lymphocyte transendothelial migration. Blood 100:2479-2486

22. Knopman DS, Siemers ER, Bain LJ, Hendrix JA, Carrillo MC (2018) National Institute on Aging - Alzheimer"s association research framework lays the groundwork for deeper understanding of Alzheimer"s disease. Alzheimers Dementia 14:261-262

23. Kuhla A, Ludwig SC, Kuhla B, Münch G, Vollmar B. Advanced glycation end products are mitogenic signals and trigger cell cycle reentry of neurons in Alzheimer's disease brain. Neurobiology of Aging. Elsevier 2015; 36(2); 753-761

24. Lloyd-Burton SM, York EM, Anwar MA, Vincent AJ, Roskams AJ (2013) SPARC regulates microgliosis and functional recovery following cortical ischemia. J. Neurosci 33:4468-4481

25. Ma CHE, Brenner GJ, Omura T, Samad OA, Costigan M, Inquimbert $P$ et al (2011) The BMP Coreceptor RGMb promotes while the endogenous BMP antagonist noggin reduces neurite outgrowth and peripheral nerve regeneration by modulating BMP signaling. J. Neurosci 31:18391-18400

26. Mattsson N, Insel PS, Palmqvist S, Stomrud E, van Westen D, Minthon L et al (2016) Increased amyloidogenic APP processing in APOE $\varepsilon 4$-negative individuals with cerebral $\beta$-amyloidosis. Nat Commun 7:10918

27. Mattsson N, Tabatabaei S, Johansson P, Hansson O, Andreasson U, Månsson J-E et al (2011) Cerebrospinal fluid microglial markers in Alzheimer's disease: elevated Chitotriosidase activity but lack of diagnostic utility. Neuromol Med 13:151-159

28. Mattsson N, Zetterberg $H$, Janelidze S, Insel PS, Andreasson U, Stomrud E et al (2016) Plasma tau in Alzheimer disease. Neurology 87:1827-1835

29. McKhann GM, Knopman DS, Chertkow H, Hyman BT, Jack CR Jr et al (2011) The diagnosis of dementia due to Alzheimer's disease: recommendations from the National Institute on Aging-Alzheimer's association workgroups on diagnostic guidelines for Alzheimer's disease. Alzheimers \& Dement 7:263-269

30. Medina MG, Ledesma MD, Domínguez JE, Medina M, Zafra D, Alameda F et al (2005) Tissue plasminogen activator mediates amyloid-induced neurotoxicity via Erk1/2 activation. EMBO J 24:1706-1716

31. Merino P, Diaz A, Jeanneret V, Wu F, Torre E, Cheng L et al (2017) Urokinase-type plasminogen activator (UPA) binding to the UPA receptor (UPAR) promotes axonal regeneration in the central nervous system. J. Biol. Chem 292:2741-2753

32. Miners JS, Baig S, Palmer J, Palmer LE, Kehoe PG, Love S (2008) SYMPOSIUM: Clearance of $A \beta$ from the Brain in Alzheimer"s Disease: $A \beta$-Degrading Enzymes in Alzheimer"s Disease. Brain Pathol 18:240-252

33. Mormino EC, Papp KV, Rentz DM, Donohue MC, Amariglio R, Quiroz YT et al (2017) Early and late change on the preclinical Alzheimer's cognitive composite in clinically normal older individuals with elevated amyloid $\beta$ Alzheimers Dement 13:1004-1012

34. Need AC, Attix DK, McEvoy JM, Cirulli ET, Linney KL, Hunt P et al (2009) A genome-wide study of common SNPs and CNVs in cognitive performance in the CANTAB. Hum Mol Genet 18:4650-4661

35. Niekisch H, Steinhardt J, Berghäuser J, Bertazzoni S, Kaschinski E, Kasper J et al (2019) Learning induces transient upregulation of brevican in the auditory cortex during consolidation of long-term memories. J. Neurosci:39(36)2499-2418

36. O'Bryant SE, Xiao G, Barber R, Huebinger R, Wilhelmsen K, Edwards $M$ et al (2011) A Blood-Based Screening Tool for Alzheimer's Disease That Spans Serum and Plasma: Findings from TARC and ADNI. PLOS ONE 6:e28092

37. Oh SB, Byun CJ, Yun J-H, Jo D-G, Carmeliet P, Koh J-Y et al (2014) Tissue plasminogen activator arrests Alzheimer's disease pathogenesis. Neurobiol Aging 35:511-519

38. Olsson B, Lautner R, Andreasson U, Öhrfelt A, Portelius E, Bjerke M et al (2016) CSF and blood biomarkers for the diagnosis of Alzheimer's disease: a systematic review and meta-analysis. Lancet Neurol 15:673-684
39. Palmqvist S, Janelidze S, Stomrud E, Zetterberg H, Karl J, Zink K et al (2019) Performance of Fully Automated Plasma Assays as Screening Tests for Alzheimer Disease-Related $\beta$-Amyloid Status. JAMA Neurol https://doi.org/1 0.1001 /jamaneurol.2019.1632

40. Palmqvist S, Schöll M, Strandberg O, Mattsson N, Stomrud E, Zetterberg H et al (2017) Earliest accumulation of $\beta$-amyloid occurs within the default-mode network and concurrently affects brain connectivity. Nat Commun 8:1214

41. Palmqvist $S$, Zetterberg $H$, Blennow K, Vestberg S, Andreasson U, Brooks DJ, Owenius R, Hägerström D, Wollmer P, Minthon L, Hansson O (2014) Accuracy of brain amyloid detection in clinical practice using cerebrospinal fluid $\beta$-amyloid 42: a cross-validation study against amyloid positron emission tomography. JAMA Neurol 71(10):1282-1289

42. Paterson RW, Heywood WE, Heslegrave AJ, Magdalinou NK, Andreasson U, Sirka E et al (2016) A targeted proteomic multiplex CSF assay identifies increased malate dehydrogenase and other neurodegenerative biomarkers in individuals with Alzheimer's disease pathology. Transl Psychiatry 6(11):e952-e952

43. Pedrini S, Gupta VB, Hone E, Doecke J, O'Bryant S, James I et al (2017) A blood-based biomarker panel indicates IL-10 and IL-12/23p40 are jointly associated as predictors of $\beta$-amyloid load in an AD cohort. Sci Rep 7:14057

44. Ramanan VK, Risacher SL, Nho K, Kim S, Shen L, McDonald BC et al (2015) GWAS of longitudinal amyloid accumulation on 18F-florbetapir PET in Alzheimer's disease implicates microglial activation gene IL1RAP. Brain 138:3076-3088

45. Ramanan VK, Saykin AJ (2013) Pathways to neurodegeneration: mechanistic insights from GWAS in Alzheimer"s disease, Parkinson"s disease, and related disorders. American Journal of Neurodegenerative Disease. e-Century Publishing Corporation 2:145-175

46. Rehker J, Rodhe J, Nesbitt RR, Boyle EA, Martin BK, Lord J et al (2017) Caspase-8, association with Alzheimer's Disease and functional analysis of rare variants. PLOS ONE 12:e0185777

47. Rohn TT, Head E, Nesse WH, Cotman CW, Cribbs DH (2001) Activation of Caspase-8 in the Alzheimer's disease brain. Neurobiol Dis 8:1006-1016

48. Seppälä TT, Nerg O, Koivisto AM, Rummukainen J, Puli L, Zetterberg $H$ et al (2012) CSF biomarkers for Alzheimer disease correlate with cortical brain biopsy findings. Neurology 78:1568-1575

49. Shabanzadeh AP, D'Onofrio PM, Monnier PP, Koeberle PD (2015) Targeting caspase- 6 and caspase- 8 to promote neuronal survival following ischemic stroke. Cell Death Dis 6:e1967-e1967

50. Shimamura M, Nakagami H, Osako MK, Kurinami $H$, Koriyama $H$, Zhengda $P$ et al (2014) OPG/RANKL/RANK axis is a critical inflammatory signaling system in ischemic brain in mice. Proc Natl Acad Sci USA 111:8191-8196

51. Shulman JM, Chen K, Keenan BT, Chibnik LB, Fleisher A, Thiyyagura P et al (2013) Genetic susceptibility for Alzheimer disease Neuritic plaque pathology. JAMA Neurol 70:1150-1157

52. Sims R, van der Lee SJ, Naj AC, Bellenguez C, Badarinarayan N, Jakobsdottir J et al (2017) Rare coding variants in PLCG2, ABI3, and TREM2 implicate microglialmediated innate immunity in Alzheimer's disease. Nat Genet 49:1373-1384

53. Steinacker P, Verde F, Fang L, Feneberg E, Oeckl P, Roeber S et al (2017) Chitotriosidase (CHIT1) is increased in microglia and macrophages in spinal cord of amyotrophic lateral sclerosis and cerebrospinal fluid levels correlate with disease severity and progression. J Neurol Neurosurg Psychiatry 41: jnnp-2017-jnn317138

54. Sweeney MD, Sagare AP, Zlokovic BV (2018) Blood-brain barrier breakdown in Alzheimer disease and other neurodegenerative disorders. Nat Rev Neurol 14:133-150

55. Tibshirani R (1996) Regression shrinkage and selection via the lasso. Journal of the Royal Statistical Society. Series B (Methodological) 58(1):267-288

56. Tucker HM, Ehmann MK, Estus S (2002) Urokinase-type plasminogen activator inhibits amyloid- $\beta$ neurotoxicity and fibrillogenesis via plasminogen. J. Neurosci. Res 70:249-255

57. Varnum MM, Kiyota T, Ingraham KL, Ikezu S, Ikezu T (2015) The antiinflammatory glycoprotein, CD200, restores neurogenesis and enhances amyloid phagocytosis in a mouse model of Alzheimer's disease. Neurobiol Aging 36:2995-3007

58. Watabe-Rudolph M, Song Z, Lausser L, Schnack C, Begus-Nahrmann Y, Scheithauer $\mathrm{MO}$ et al (2012) Chitinase enzyme activity in CSF is a powerful biomarker of Alzheimer disease. Neurology 78:569-577

59. Weber C, Fraemohs L, Dejana E (2007) The role of junctional adhesion molecules in vascular inflammation. Nat Rev Immunol 7:467-477

60. Wei W, Norton DD, Wang X, Kusiak JW (2002) A $\beta$ 17-42 in Alzheimer's disease activates JNK and caspase-8 leading to neuronal apoptosis. Brain 125:2036-2043 
61. Wetzel-Smith MK, Hunkapiller J, Bhangale TR, Srinivasan K, Maloney JA, Atwal JK et al (2014) A rare mutation in $<i>U N C 5 C</ i>$ predisposes to lateonset Alzheimer's disease and increases neuronal cell death. Nat Med 20: 1452-1457

62. Wong MW, Braidy N, Poljak A, Pickford R, Thambisetty M, Sachdev PS (2017) Dysregulation of lipids in Alzheimer's disease and their role as potential biomarkers. Alzheimers Dement 13:810-827

63. Yaffe K, Lindquist $K$, Schwartz AV, Vitartas C, Vittinghoff E, Satterfield $S$ et al (2011) Advanced glycation end product level, diabetes, and accelerated cognitive aging. Neurology 77:1351-1356

\section{Publisher's Note}

Springer Nature remains neutral with regard to jurisdictional claims in published maps and institutional affiliations.

Ready to submit your research? Choose BMC and benefit from:

- fast, convenient online submission

- thorough peer review by experienced researchers in your field

- rapid publication on acceptance

- support for research data, including large and complex data types

- gold Open Access which fosters wider collaboration and increased citations

- maximum visibility for your research: over $100 \mathrm{M}$ website views per year

At BMC, research is always in progress.

Learn more biomedcentral.com/submissions 